\title{
'Short' double-balloon enteroscope for endoscopic retrograde cholangiopancreatography in patients with a surgically altered upper gastrointestinal tract
}

\author{
S Cho MBBS, P Kamalaporn MD, G Kandel MD, P Kortan MD, N Marcon MD, G May MD
}

S Cho, P Kamalaporn, G Kandel, P Kortan, N Marcon, G May. 'Short' double-balloon enteroscope for endoscopic retrograde cholangiopancreatography in patients with a surgically altered upper gastrointestinal tract. Can J Gastroenterol 2011;25(11):615-619.

BACKGROUND: Endoscopic retrograde cholangiopancreatography (ERCP) remains a challenge for endoscopists in patients with surgically altered anatomy of the upper gastrointestinal tract. Double-balloon enteroscopes (DBEs) have revolutionized the ability to access the small bowel. The indication for its therapeutic use is expanding to include ERCP for patients who have undergone small bowel reconstruction. Most of the published experiences in DBE-assisted ERCP have used conventional double-balloon enteroscopes that are $200 \mathrm{~cm}$ in length, which do not permit use of the standard ERCP accessories. The authors report their experience with DBE-assisted ERCP using a 'short' DBE in patients with surgically altered anatomy.

METHODS: A retrospective review of patients with previous small bowel reconstruction who underwent ERCP with a 'short' DBE at the Centre for Therapeutic Endoscopy and Endoscopic Oncology (Toronto, Ontario) between February 2007 and November 2008 was performed.

RESULTS: A total of 20 patients (10 men) with a mean age of 57.9 years (range 26 to 85 years) underwent 29 sessions of ERCP with a DBE. Six patients underwent Billroth II gastroenterostomy, seven patients Roux-en-Y hepaticojejunostomy, five patients Roux-en-Y gastrojejunostomy, one patient Roux-en-Y esophagojejunostomy and one patient a Whipple's operation with choledochojejunostomy. Some patients $(n=12$ [60\%]) underwent previous attempts at ERCP in which the papilla of Vater or bilioenteric anastomosis could not be reached with either a duodenoscope or pediatric colonoscope. All procedures were performed with a commercially available DBE (working length $152 \mathrm{~cm}$, distal end diameter $9.4 \mathrm{~mm}$, channel diameter $2.8 \mathrm{~mm}$ ). The procedures were performed under conscious sedation with intravenous midazolam, fentanyl and diazepam, except in one patient in whom general anesthesia was administered. Either the papilla of Vater or bilioenteric anastomosis was reached in 25 of 29 cases (86.2\%) in a mean duration of $20.8 \mathrm{~min}$ (range $5 \mathrm{~min}$ to $82 \mathrm{~min}$ ). Bile duct cannulation was successful in 24 of 25 cases in which the papilla or bilioenteric anastomosis was reached. Therapeutic interventions were successful in 15 patients (24 procedures) including sphincterotomy $(n=7)$, stone extraction $(n=9)$, biliary dilation $(n=8)$, stent placement $(n=9)$ and stent removal $(n=8)$. The mean total duration of the procedures was $70.7 \mathrm{~min}$ (range $30 \mathrm{~min}$ to $117 \mathrm{~min}$ ). There were no procedure-related complications.

CONCLUSION: DBEs enable successful diagnostic and therapeutic ERCP in patients with a surgically altered anatomy of the upper gastrointestinal tract. It is a safe, feasible and less invasive therapeutic option in this group of patients. Standard 'long' DBEs have limitations of long working length and the need for modified ERCP accessories. 'Short' DBEs are equally as effective in reaching the target limb as standard 'long' DBEs, and overcomes some limitations of long DBEs to result in high success rates for endoscopic therapy.

Key Words: Double-balloon enteroscope; ERCP; Surgically altered upper gastrointestinal tract

\author{
Un entéroscope à double ballon « court » pour \\ effectuer une cholangiopancréatographie rétrograde \\ endoscopique chez des patients dont les voies \\ œesogastroduodénales sont modifiées par une opération
}

HISTORIQUE : La cholangiopancréatographie rétrograde endoscopique (CPRE) demeure problématique pour les endoscopistes qui doivent l'effectuer chez des patients dont l'anatomie des voies œesogastroduodénales est modifiée par une opération. Les entéroscopes à double ballon (EDB) ont révolutionné l'accès à l'intestin grêle. L'indication de son usage thérapeutique s'étend pour inclure la CPRE chez les patients qui ont subi une reconstruction du grêle. La plupart des expériences publiées sur la CPRE assistée par EDB faisaient appel aux EDB classiques d'une longueur de $200 \mathrm{~cm}$, qui ne permettent pas d'utiliser les accessoires standards de la CPRE. Les auteurs exposent leur expérience de la CPRE assistée par EDB au moyen d'un EDB « court » chez des patients dont l'anatomie a été modifiée par une opération. MÉTHODOLOGIE : Les chercheurs ont procédé à une analyse rétrospective des patients présentant une reconstruction du grêle qui ont subi une CPRE au moyen d'un EDB « court » au Centre for Therapeutic Endoscopy and Endoscopic Oncology deToronto, en Ontario, entre février 2007 et novembre 2008.

RÉSULTATS : Au total, 20 patients (dix hommes) d'un âge moyen de 57,9 ans (plage de 26 à 85 ans) ont subi 29 séances de CPRE au moyen d'un EDB. Six patients ont subi une gastroentérostomie de type Billroth II, sept patients, une hépaticojéjunostomie Roux-en-Y, cinq patients, une gastrojéjunostomie Roux-en-Y, un patient, une œesophagojéjunostomie Rouxen-Y et un patient, une opération de Whipple accompagnée d'une cholédochojéjunostomie. Certains patients $(\mathrm{n}=12$ [60 \%]) avaient déjà subi des tentatives de CPRE, et il avait été impossible d'atteindre la papille de Vater ou l'anastomose bilioentérique à l'aide du duodénoscopeou du coloscope pédiatrique. Toutes les interventions ont été effectuées au moyen d'un EDP offert sur le marché (dimension de $152 \mathrm{~cm}$, diamètre de l'extrémité distale de $9,4 \mathrm{~mm}$, diamètre interne de 2,8 mm). Les interventions ont été effectuées sous sédation locale au moyen de midazolam, de fentanyl et de diazépam par voie intraveineuse, sauf chez un patient qui l'a subie sous anesthésie générale.On a atteint la papille de Vater ou l'anastomose bilioentérique dans 25 des 29 cas (86,2\%) en une moyenne de 20,8 minutes (plage de cinq minutes à 82 minutes). La canulation du canal cholédoque a été réussie dans 24 des 25 cas où on a atteint la papille ou l'anastomose bilioentérique. Les interventions thérapeutiques ont été concluantes chez 15 patients ( 24 interventions), y compris une sphinctérotomie $(n=7)$, l'extraction de calculs $(n=9)$, une dilatation biliaire $(n=8)$, l'installation d'une endoprothèse $(n=9)$ et le retrait d'une endoprothèse $(n=8)$. Les interventions avaient une durée totale moyenne de 70,7 minutes (plage de 30 minutes à 117 minutes). Aucune complication n'était liée à l'intervention.

CONCLUSION : Les EDB permettent d'effectuer une CPRE diagnostique et thérapeutique chez des patients dont l'anatomie des voies œsogastroduodénales a été modifiée par une opération. C'est une option thérapeutique sécuritaire, faisable et moins effractive au sein de ce groupe de patients. Les $\mathrm{EDB}$ « longs » standards s'associent aux limites d'un travail prolongé et à la nécessité de modifier les accessoires de CPRE. Les EDB « courts » atteignent le foyer ciblé de manière tout aussi efficace et vainquent certaines des limites des EDB longs, assurant ainsi un taux de succès élevé de la thérapie endoscopique.

The Centre for Therapeutic Endoscopy and Endoscopic Oncology, Division of Gastroenterology, St Michael's Hospital, University of Toronto, Toronto,

Ontario

Correspondence: Dr Sarah Cho, Department of Gastroenterology, Royal North Shore Hospital, St Leonards 2065, Australia. Telephone 612-99068973,

fax612-94383220, e-mail scho74@hotmail.com

Received for publication January 7, 2010. Accepted March 21, 2011 
$E_{a}^{\text {nd }}$ doscopic retrograde cholangiopancreatography (ERCP) remains challenge for endoscopists in patients with surgically altered anatomy of the upper gastrointestinal tract. Because the main problem with access to the papilla of Vater or enteral anastomosis of the biliary or pancreatic duct is the length of bowel that needs to be traversed, variable approaches including the use of endoscopic instruments other than a standard duodenoscope (ie, pediatric colonoscope or push enteroscope), have been used in the past with limited success, frequently leading to percutaneous transhepatic cholangiography (PTC) or operative intervention (1-5).

The double-balloon enteroscope (DBE) has revolutionized the ability to access the small bowel, and is now widely used in the diagnosis and treatment of obscure gastrointestinal bleeding (6-7). The indication for its therapeutic use has recently expanded, and its use in balloon dilation of small bowel strictures, polypectomy and endoscopic submucosal resection has been described (7-11). The DBE can also be used to facilitate ERCP in patients who have undergone a variety of small bowel reconstruction procedures. However, the use of ERCP accessories is limited for a conventional DBE due to its length. We evaluated the use of 'short' DBE, which allows the use of standard ERCP accessories, for ERCP in patients with a surgically altered upper gastrointestinal tract.

\section{METHODS}

A retrospective review of the patients with previous small bowel reconstruction who underwent ERCP with a short DBE at The Centre for Therapeutic Endoscopy and Endoscopic Oncology at St Michael's Hospital (Toronto, Ontario) between February 2007 and November 2008, was performed. All procedures were performed with a DBE (working length $152 \mathrm{~cm}$, distal-end diameter $9.4 \mathrm{~mm}$, channel diameter $2.8 \mathrm{~mm}$ [Fujinon EC-450BI5, Fuji Photo Optical Co Ltd, Japan]). A standard transparent straight viewing cap (Olympus Co Ltd, Japan) was taped onto the end of the DBE to enhance visibility. All procedures were performed in patients who were under conscious sedation with intravenous midazolam, fentanyl and diazepam, except in one patient in whom general anesthesia was administered. All procedures were performed at St Michael's Hospital (Toronto, Ontario). Once the papilla or bilioenteric anastomosis was reached, standard ERCP accessories were used for cannulation and therapeutic interventions.

\section{RESULTS}

A total of 20 patients ( 10 men), with a mean age of 58 years (range 26 to 85 years), underwent ERCP with a DBE. Six patients had undergone Billroth II gastroenterostomy, seven patients Roux-en-Y hepaticojejunostomy, five patients Roux-en-Y gastrojejunostomy, one patient esophagojejunostomy and one patient a Whipple resection with choledochojejunostomy. Twelve patients (60\%) underwent previous attempts at ERCP in which the papilla of Vater or bilioenteric anastomosis could not be reached with either a duodenoscope or pediatric colonoscope. Five patients required one or more repeat ERCP procedures for repeat intervention or follow-up; therefore, a total of 29 'short' DBE-assisted ERCP procedures were performed in these 20 patients. The indications for ERCP are listed in Table 1.

Either the papilla of Vater or bilioenteric anastomosis was reached in a mean duration of $20.8 \mathrm{~min}$ (range $5 \mathrm{~min}$ to $82 \mathrm{~min}$ ) in 25 of 29 cases $(86.2 \%)$. In four patients, the papilla of Vater or bilioenteric anastomosis could not be reached due to either a long Roux limb in one patient (previous gastric bypass) or acute angulation of the afferent limb in three patients (one patient with esophagojejunostomy, one patient with hepaticojejunostomy and one patient with a previous Whipple resection). Bile duct cannulation was successful in 24 of 25 cases in which the papilla or bilioenteric anastomosis was reached. Therapeutic interventions were successful in 24 cases (15 patients) including sphincterotomy $(n=7)$, balloon dilation of biliary sphincter $(n=4)$, stone extraction $(n=9)$, biliary stricture dilation $(n=8)$, stent placement $(n=9)$ and stent removal $(n=8)$ (Table 2, Figures 1, 2 and 3). The mean total duration of the procedure was $70.7 \mathrm{~min}$ (range $30 \mathrm{~min}$ to $117 \mathrm{~min}$ ). Although several patients experienced some abdominal discomfort immediately following the procedure, it resolved by the next day in all cases, with no biochemical evidence of pancreatitis or other procedure-related complications.

\section{DISCUSSION}

Some patients who have undergone Roux-en-Y surgery have very long Roux limbs. Such procedures include Roux-en-Y gastric bypass, Roux-en-Y hepaticojejunostomy for orthotopic liver transplantation or major bile duct reconstruction. In some patients with Whipple resection or Billroth II partial gastrectomy, the afferent limb is long or tightly angulated. In these patients, it is often impossible to perform ERCP using a standard duodenoscope, pediatric colonoscope or push enteroscope, especially when coupled with underlying adhesions, which are often present as a consequence of the original surgery. To overcome the length of standard endoscopes, ERCP through gastrostomy or jejunostomy tracts has been reported following failed attempts at ERCP per oral anatomical route in these patients (12-15). This technique, however, is more invasive than other purely endoscopic approaches, requires combined surgical and endoscopic expertise, and is associated with risks related to anesthesia and surgery. Furthermore, unless ERCP is performed intraoperatively, it may be impractical to wait for the stoma to mature if patients are acutely ill. PTC is less invasive than surgery and may be a good option for patients who are not fit to undergo surgery; however, it has technical limitations in patients without a dilated intrahepatic bile duct and/or those with ascites (16). In addition, PTC is not a practical procedure in patients with pancreatic disease (17).

The length and flexibility of the enteroscope, coupled with a double-balloon system, allows access through distorted small bowel anatomy to reach native papilla of Vater or biliopancreaticoenteric anastomoses. Following early case reports - including Haruta et al (18) who performed an endoscopic balloon dilation of bilioenteric anastomotic stricture in a patient after liver transplantation - in recent years, there has been increasing experience with DBE-assisted ERCP using a standard DBE $200 \mathrm{~cm}$ in length in patients who have undergone Roux-en-Y surgery; high success rates without immediate or short-term complications have been reported. The success rate to reach the papilla of Vater or the biliopancreaticoenteric anastomosis ranges from $64 \%$ to $100 \%$ in published reports (19-25). These figures are superior compared with the $33 \%$ to $67 \%$ success rates using standard endoscopic instruments of the pre-DBE era $(26,27)$. DBE-assisted ERCP with a standard DBE $200 \mathrm{~cm}$ in length in patients with Billroth II reconstruction has also shown to be effective $(25,28)$. The results of the published reports (with $>10$ patients) of DBE-assisted ERCP in altered surgical anatomy using the standard $200 \mathrm{~cm} \mathrm{DBE}$ are summarized in Table 3.

There are three different types of DBE that are commercially available (Table 4). Although the standard $200 \mathrm{~cm}$ therapeutic DBE has been shown to be effective in gaining access to the targeted limb, entry into the native papilla, bilioenteric or pancreaticoenteric anastomosis is not always possible. Failures in intended therapy have also been reported in published studies $(22,24,25)$. There are several possible explanations for this finding. First, a standard DBE has a long working length, making endoscopic manipulation difficult. Second, due to their inadequate length, most standard ERCP accessories cannot be used, thus making cannulation and subsequent manipulation of the targeted duct more technically difficult. Third, a DBE is a forward viewing instrument; hence, it is not designed for ERCP.

A 'short' therapeutic DBE, which is $152 \mathrm{~cm}$ in length, overcomes some of the problems associated with manipulation of a long instrument and allows ERCP accessories of standard length to be used. The ability of a short DBE to reach the papilla of Vater or biliopancreaticoenteric anastomosis is comparable with and even slightly superior with that of a $200 \mathrm{~cm} \operatorname{DBE}(29,30)$. Our study demonstrated a high success rate $(100 \%)$ for short DBEs in performing a wide range of endoscopic therapy during ERCP once the papilla or bilioenteric anastomosis 
TABLE 1

\section{Patient characteristics $(n=20)$}

\begin{tabular}{lc}
\hline Characteristic & $\mathbf{n}$ \\
\hline Mean age, years & 58 (range 26 to 85) \\
Sex, male:female & $10: 10$ \\
Previous surgery ( $\mathrm{n}=20$ ) & \\
Roux-en-Y hepaticojejunostomy & 7 \\
Billroth II gastroenterostomy & 6 \\
Roux-en-Y gastojejunostomy & 5 \\
Roux-en-Y esophagojejunostomy & 1 \\
Whipple with choledochojejunostomy & 1 \\
Indications for ERCP (n=29) & \\
Choledocholithiasis & 10 \\
Stricture & 8 \\
Cholangitis & 8 \\
Follow-up ERCP & 2 \\
Bile leakage & 1 \\
\hline
\end{tabular}

ERCP Endoscopic retrograde cholangiopancreatography

\section{TABLE 2}

Therapeutic interventions performed

\begin{tabular}{ll}
\hline Intervention & n \\
\hline Biliary sphincterotomy & 7 \\
Balloon dilation of biliary sphincter & 4 \\
Stone extraction & 9 \\
Balloon dilation of biliary stricture & 8 \\
Biliary stent placement & 9 \\
Biliary stent removal & 8 \\
\hline
\end{tabular}

was reached. Shimatani et al (29) recently reported similar success with short DBE-assisted ERCP. A review of 103 ERCP procedures performed in 68 patients demonstrated a 97\% success rate in obtaining cholangiograms. Endoscopic treatment was achieved in all patients following cholangiograms (100\%). The results of the two published studies of short DBE-assisted ERCP are summarized in Table 5.

Despite the mechanical advantages of both short and long DBEs in reaching the target limb (considering the significant distance away from the mouth and beyond the tight angulation of the anastomosis), technical challenges associated with performing ERCP with a forwardviewing instrument remain because it is usually not possible to achieve an 'en face' view of the native papilla. We were unable to achieve cannulation in one of 25 cases. Even if the end of the target limb is reached with a DBE, failure to locate either native papilla or bilioenteric anastomosis has been reported. This may be aided by the use of a transparent cap attached to the end of the DBE, which enhances visibility and aids in inspecting small bowel mucosa between folds. The transparent cap was used in all cases of our study. Shimatani et al (29) reported its use in cases for which cannulation was difficult. In seven of our cases that required sphincterotomy, needle-knife sphincterotomy over the stent following stent placement was performed to overcome the absence of an elevator. To minimize the risk of perforation, balloon dilation of up to $8 \mathrm{~mm}$ to $10 \mathrm{~mm}$ was performed after a partial sphincterotomy in four of seven patients for removal of larger stones. Although most ERCP accessories can be used for short therapeutic DBEs, adaptation of accessories for the standard $200 \mathrm{~cm}$ therapeutic DBE would further improve the utility of DBE ERCP, especially in patients with long Roux-en-Y limbs in which the anastomosis or papilla cannot be reached with a short DBE.

More recently, there has been an increasing number of reports describing the use of a single-balloon enteroscope (SBE) for ERCP in patients with altered small bowel anatomy. The largest case series to date was reported by Saleem et al (31). A total of 50 patients with a Roux-en-Y anastomosis underwent 56 ERCP procedures using an SBE. Overall diagnostic success was achieved in 39 of 56 cases (70\%).

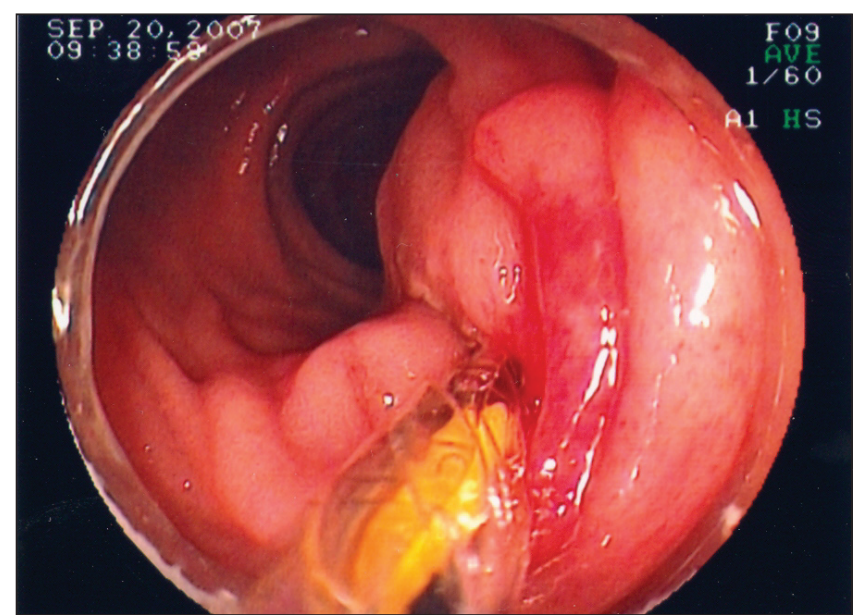

Figure 1) Endoscopic image of balloon dilation of a hepaticojejunostomy

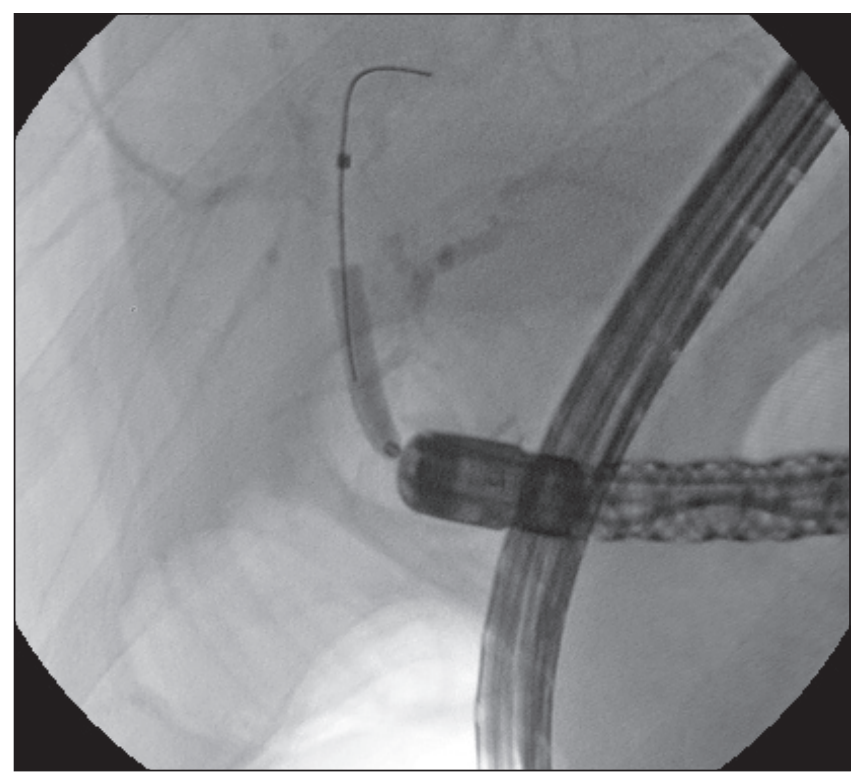

Figure 2) X-ray image of balloon dilation of a hepaticojejunostomy

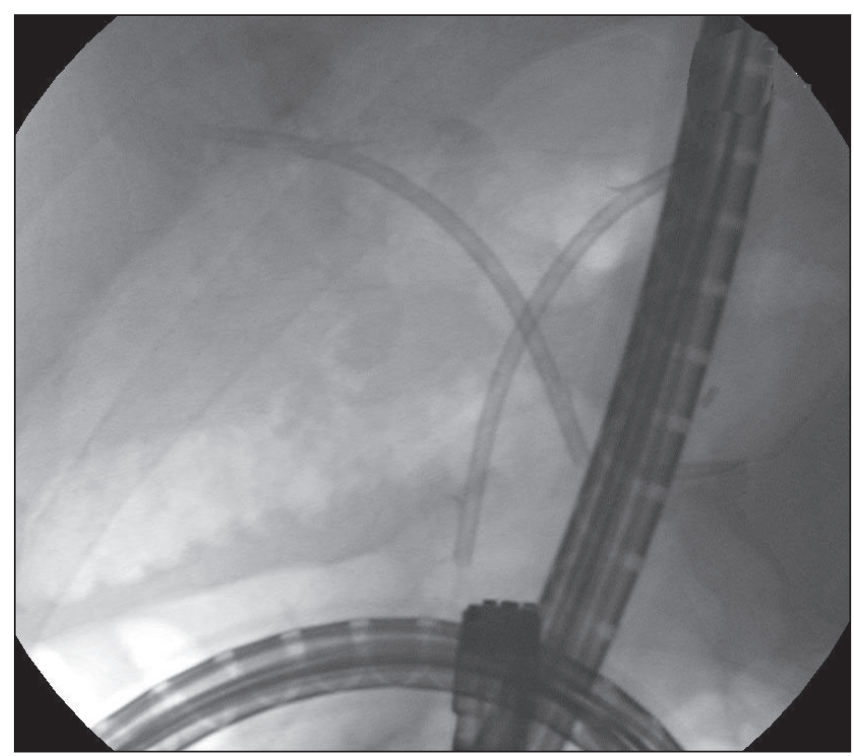

Figure 3) X-ray image of plastic biliary stent placement using double-balloon enteroscopy 
TABLE 3

Summary of reports of 'long' double-balloon enteroscope-assisted endoscopic retrograde cholangiopancreatography in altered small bowel anatomy

\begin{tabular}{|c|c|c|c|c|c|}
\hline \multirow[b]{2}{*}{ Author (reference), year } & \multirow[b]{2}{*}{ Patients, n } & \multirow[b]{2}{*}{ Anatomy } & \multicolumn{2}{|c|}{ Success, \% } & \multirow[b]{2}{*}{ Complications } \\
\hline & & & Diagnostic & Therapeutic & \\
\hline Emmett and Mallat (19), 2007 & 14 & Roux-en-Y & 80 & 100 & None \\
\hline Aabakken et al (21), 2007 & 18 & Various & 83 & 100 & None \\
\hline Moreels et al (22), 2007 & 22 & Roux-en-Y & 87 & 74 & 1 retroperitoneal air \\
\hline Maaser et al (23), 2008 & 11 & Various & 63 & 100 & None \\
\hline Moannkemueller et al (24), 2008 & 11 & Various & 82 & 70 & 1 perforation \\
\hline Parlak and Cicek (25), 2010 & 14 & Roux-en-Y & 93 & 92 & 1 retroperitoneal air \\
\hline
\end{tabular}

TABLE 4

Specifications of double-balloon enteroscopes and overtubes

\begin{tabular}{|c|c|c|c|}
\hline \multirow[b]{2}{*}{ Specification } & \multicolumn{3}{|c|}{ Endoscope* } \\
\hline & EN-450P5/20 & EN-450T5/W & EC-450BI5 \\
\hline Diameter, mm & 8.5 & 9.4 & 9.4 \\
\hline Working channel, mm & 2.2 & 2.8 & 2.8 \\
\hline \multirow[t]{3}{*}{ Working length, mm } & 2000 & 2000 & 1520 \\
\hline & \multicolumn{3}{|c|}{ Overtube* } \\
\hline & TS-12140 & TS-13140 & TS-13101 \\
\hline Diameter, mm & 12.2 & 13.2 & 13.2 \\
\hline Length, mm & 1450 & 1450 & 1050 \\
\hline
\end{tabular}

${ }^{*}$ Fuji Photo Optical Co Ltd, Japan

TABLE 5

Summary of reports of 'short' double-balloon enteroscope-assisted endoscopic retrograde cholangiopancreatography in altered small bowel anatomy

\begin{tabular}{|c|c|c|c|c|c|}
\hline \multirow[b]{2}{*}{ Author (reference), year } & \multirow[b]{2}{*}{ Patients, $\mathbf{n}$} & \multirow[b]{2}{*}{ Anatomy } & \multicolumn{2}{|c|}{ Success, \% } & \multirow[b]{2}{*}{ Complications } \\
\hline & & & Diagnostic & Therapeutic & \\
\hline Present study & 20 & Various & 83 & 100 & None \\
\hline Shimatani et al (29), 2009 & 68 & Various & 97 & 100 & 5 perforation $^{\dagger}$ \\
\hline Tsujino et al (30), 2010 & 6 & Roux-en-Y & $100 *$ & 100 & 1 retroperitoneal air \\
\hline
\end{tabular}

*One patient required combined percutaneous-endoscopic technique; ${ }^{\dagger}$ Four patients managed conservatively, and one patient required laparotomy

TABLE 6

Summary of reports of single-balloon enteroscope-assisted endoscopic retrograde cholangiopancreatography in altered small bowel anatomy

\begin{tabular}{|c|c|c|c|c|c|}
\hline \multirow[b]{2}{*}{ Author (reference), year } & \multirow[b]{2}{*}{ Patients, n } & \multirow[b]{2}{*}{ Anatomy* } & \multicolumn{2}{|c|}{ Success, \% } & \multirow[b]{2}{*}{ Complications } \\
\hline & & & Diagnostic & Therapeutic & \\
\hline Neumann et al (32), 2009 & 13 & Roux-en-Y & 62 & 54 & None \\
\hline Wang et al (33), 2010 & 16 & Various & 92 & 90 & 2 pancreatitis \\
\hline Saleem et al (31), 2010 & 50 & RouX-en-Y & 70 & 91 & None \\
\hline
\end{tabular}

*No patients with Roux-en-Y

Therapeutic success was achieved in 21 of 23 cases (91\%). The results of the published studies of SBE-assisted ERCP are summarized in Table 6. A randomized comparison of DBE with SBE in ERCP is not yet available. SBEs are $200 \mathrm{~cm}$ in length and, therefore, have same restrictions as DBEs that are $200 \mathrm{~cm}$ in length in terms of their inability to use standard ERCP accessories.

\section{CONCLUSION}

Experience with using DBEs to perform ERCP is increasing in patients with a surgically altered upper gastrointestinal tract. It is a safe, effective and less invasive diagnostic and therapeutic option for this group of patients than PTC or surgery. Standard long DBEs have limitations of long working length and the need for modified ERCP accessories. Short DBEs are equally as effective in reaching the target limb as standard long DBEs, and overcome some of its limitations to result in high success rates for endoscopic therapy. The present study adds to the growing literature on the utility of short DBEs for the diagnosis and treatment of pancreaticobiliary disorders in patients with surgically altered anatomy.

\section{REFERENCES}

1. Suisse A, Yassin K, Lavy A, et al. Outcome and early complications of ERCP: A prospective single center study. Hepatogastroenterology 2005;52:352-5.

2. Chahal P, Baron TH, Topazian MD, et al. ERCP in post-Whipple patients. Endoscopy 2006;38:1241-5.

3. Feitoza AB, Baron TH. Endoscopy and ERCP in the setting of previous upper GI tract surgery. Gastrointest Endsoc 2002;55:75-9.

4. Wright BE, Cass OW, Freeman ML. ERCP in patients with long-limb Roux-en-Y gastrojejunostomy and intact papilla. Gastrointest Endosc 2002;56:225-32.

5. Elton E, Hanson BL, Qaseem T, et al. Diagnostic and therapeutic ERCP using an enteroscope and a pediatric colonoscope in long-limb surgical bypass patients. Gastrointest Endosc 1998;47:62-7.

6. Yamamoto H, Sekine Y, Sato Y, et al. Total enteroscopy with a nonsurgical steerable double-balloon method. Gastrointest Endosc 2001;53:216-20.

7. Heine GD, Hadithi M, Groenen MJ, et al. Double-balloon enteroscopy: Indications, diagnostic yield, and complications in a series of 275 patients with suspected small-bowel disease. Endoscopy 2006;38:42-8. 
8. Zhong J, Ma T, Zhang C, et al. A retrospective study of the application on double-balloon enteroscopy in 378 patients with suspected small-bowel diseases. Endoscopy 2007;39:208-15.

9. Mehdizadeh S, Ross A, Gerson L, et al. What is the learning curve associated with double-balloon enteroscopy? Technical details and early experience in 6 U.S. tertiary care centers. Gastrointest Endosc 2005;61:AB238. (Abst)

10. Kuno A, Yamamoto H, Kita H, et al. Double-balloon enteroscopy through a Roux-en-Y anastomosis for EMR of an early carcinoma in the afferent duodenal limb. Gastrointest Endosc 2004;60:1032-4.

11. Yamamoto H. Endoscopic submucosal dissection of early cancers and large flat adenomas. Clin Gastroenterol Hepatol 2005;3:574-6.

12. Matlock J, Ikramuddin S, Lederer H, et al. Bypassing the bypass: ERCP via gastrostomy after bariatric surgery. Gastrointest Endosc 2005;61:AB98. (Abst)

13. Baron TH, Chahal P, Ferreira LE. ERCP via mature feeding jejunostomy tube tract in a patient with Roux-en-Y anatomy. Gastrointest Endosc 2008;68:189-91.

14. Peters M, Papasavas PK, Caushaj PF, et al. Laparoscopic transgastric Endoscopic retrograde cholangiopancreatography for benign common bile duct stricture after Roux-en-Y gastric bypass. Surg Endosc 2002;16:1106.

15. Pimentel RR, Mehran A, Szomstein S, et al. Laparoscopy-assisted transgastrostomy ERCP after bariatric surgery: Case report of a novel approach. Gastrointest Endosc 2004;59:325-8.

16. Teplick SK, Flick P, Brandon JC. Transhepatic cholangiography in patients with suspected biliary disease and nondilated intrahepatic bile ducts. Gastrointest Radiol 1991;16:193-7.

17. Chahal P, Baron TH, Topazian MD, et al. ERCP in post-Whipple patients. Endoscopy 2006;38:1241-5.

18. Haruta H, Yamamoto H, Mizuta K, et al. A case of successful enteroscopic balloon dilation for late anastomotic stricture of choledochojejunostomy after living donor liver transplantation. Liver Transpl 2005;11:1608-10.

19. Emmett DS, Mallat DB. Double-balloon ERCP in patients who have undergone Roux-en-Y surgery: A case series. Gastrointest Endosc 2007; 66:1038-41.

20. Spahn TW, Grosse-Thie W, Spies P, Mueller MK. Treatment of choledocholithiasis following Roux-en-Y hepaticojejunostomy using double-balloon endoscopy. Digestion 2007;75:20-1.
21. Aabakken L, Bretthauer M, Line PD. Double-balloon enteroscopy for endoscopic retrograde cholangiography in patients with a Roux-en-Y anastomosis. Endoscopy 2007;39:1068-71.

22. Moreels TG, Roth B, Vandervliet EJ, Parizel PM, Dutré J, Pelckmans PA. The use of the double-balloon enteroscope for endoscopic retrograde cholangiopancreatography and biliary stent placement after Roux-en-Y hepaticojejunostomy. Endoscopy 2007;39(Suppl 1):E196-7.

23. Maaser C, Lenze F, Bokemeyer M, et al. Double balloon enteroscopy: A useful tool for diagnostic and therapeutic procedures in the pancreaticobiliary system. Am J Gastroenterol 2008;103:894-900.

24. Moannkemueller K, Bellutti M, Neumann H, Malfertheiner P. Therapeutic ERCP with the double-balloon enteroscope in patients with Roux-en-Y anastomosis. Gastrointest Endosc 2008;67:992-6.

25. Parlak E, Cicek B. Endoscopic retrograde cholangiography by double balloon enteroscopy in patients with Roux-en-Y hepaticojejunostomy. Surg Endosc 2010;24:894-900.

26. Hintze RE, Adler A, Veltzke W, et al. Endoscopic access to the papilla of Vater for ERCP in patients with Billroth II or Roux-en-Y gastrojejunostomy. Endoscopy 1997;29:69-73.

27. Wright BE, Cass OW, Freeman ML. ERCP in patients with long-limb Roux-en-Y gastrojejunostomy and intact papilla. Gastrointest Endosc 2002;56:225-32.

28. Chu YC, Su SJ, Yang CC, Yeh YH, Chen CH, Yueh SK. ERCP plus papillotomy by use of double-balloon enteroscopy after Billroth II gastrectomy. Gastrointest Endosc 2007;66:1234-6.

29. Shimatani M, Matsushita M, Takaoka M, et al. Effective "short" double-balloon enteroscope for diagnostic and therapeutic ERCP in patients with altered gastrointestinal anatomy: A large case series. Endoscopy 2009;41:849-54.

30. Tsujino T, Yamada A, Isayama H, et al. Experiences of biliary interventions using short double-balloon enteroscopy in patients with Roux-en-Y. Digest Endosc 2010;22:211-6.

31. Saleem A, Baron TH, Gostout CJ, et al. Endoscopic retrograde cholangiopancreatography using a single-balloon enteroscope in patients with altered Roux-en-Y anatomy. Endoscopy 2010;42:656-60.

32. Neumann H, Fry LC, Meyer F, et al. Endoscopic retrograde cholangiopancreatography using the single balloon enteroscope technique in patients with Roux-en-Y anastomosis. Digestion 2009;80:52-7.

33. Wang AY, Sauer BG, Behm BW, et al. Single-balloon enteroscopy effectively enables diagnostic and therapeutic retrograde cholangiography in patients with surgically altered anatomy. Gastrointest Endosc 2010;71:641-9. 


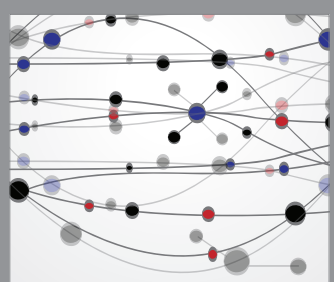

The Scientific World Journal
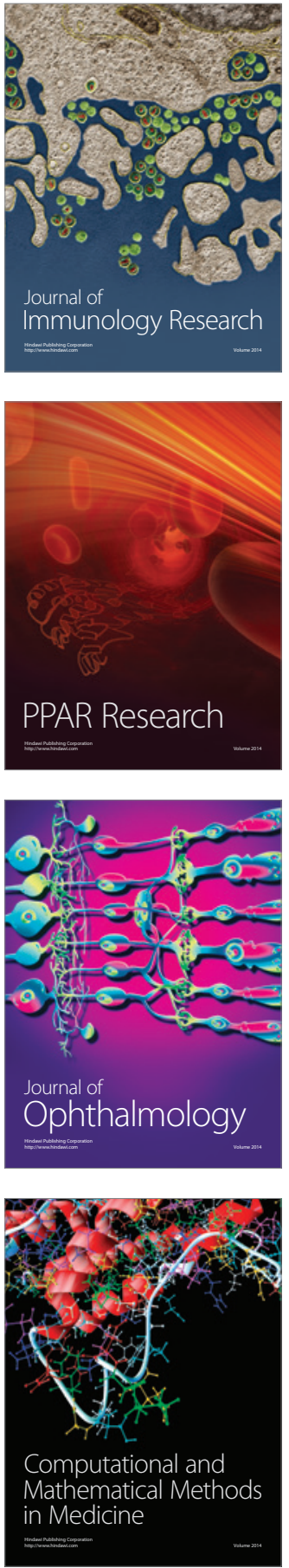

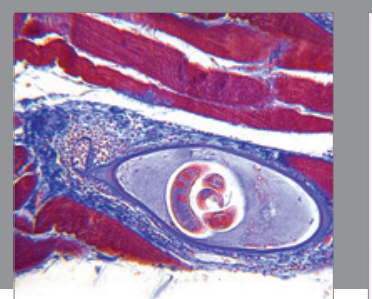

Gastroenterology Research and Practice

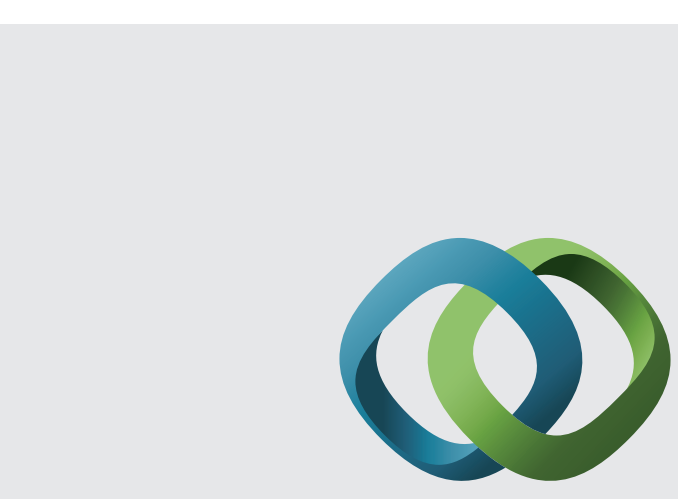

\section{Hindawi}

Submit your manuscripts at

http://www.hindawi.com
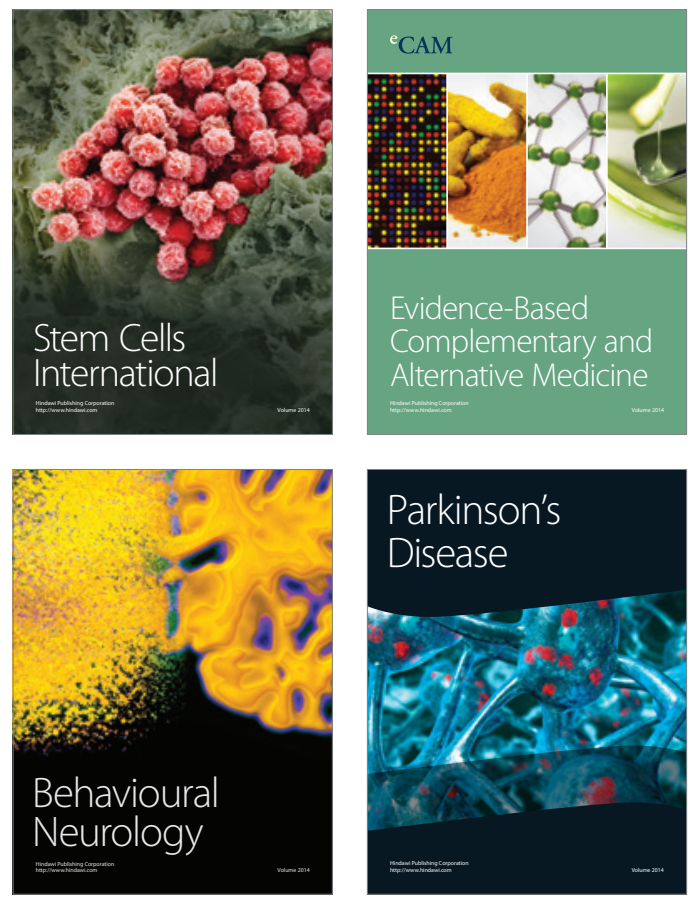
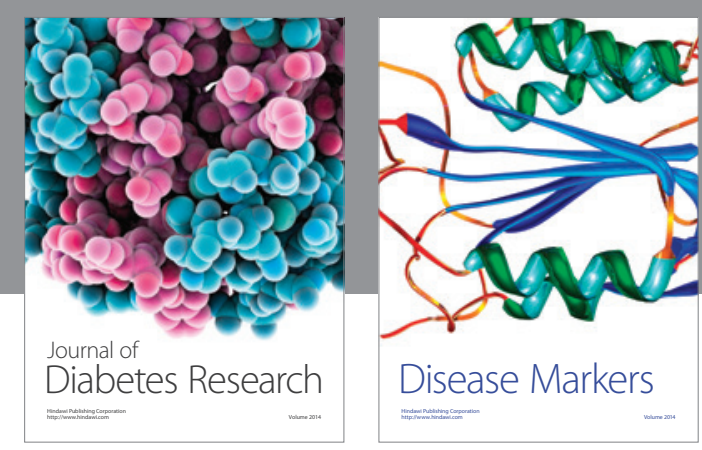

Disease Markers
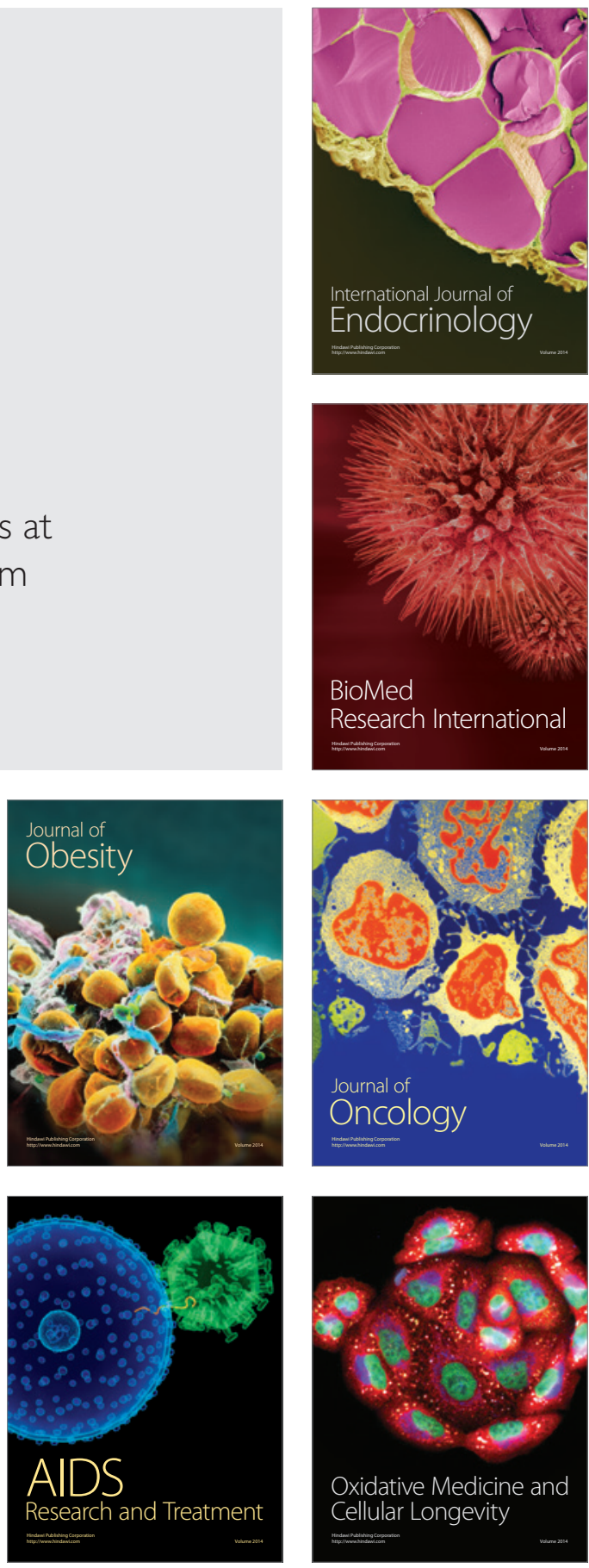